\title{
Bringing research back to life
}

Having all but killed it off, the British government is now brooding on the question of how best to restore a oncesuccessful research enterprise to good health.

THE familiar cry of "What can be done to rescue British science?" seems about to be taken up by an unfamiliar voice - that of the British government, the chief source of the torments of the past decade. Even before next year's British budget had been made public (on Tuesday) by the new Chancellor of the Exchequer, Mr John Major, civil servants were brooding on what will happen a year from now.

The difficulty is that the answer to the question is no longer budgetary. If the value of research grants were forthwith doubled, that would not restore the research enterprise to good health. Nor would it help decisively if the funds available for research support allowed a greater proportion of those with bright ideas to succeed. What began as fiscal attrition (to be fair to the present government, in the early 1970s) became enforced decimation as research councils and universities were compelled to cut back on their establishments. Seen from the bench, the outstanding weakness of British science now is that there are too few good people competing for such resources as there are, and far too few outstanding research groups to which able ambitious people wish to attach themselves.

The seriousness of this state of affairs, however subjectively assessed, cannot be underestimated. The most productive and imaginative laboratories are those from which the most able researchers graduate in the greatest numbers. Rutherford's Cavendish Laboratory at Cambridge was a legend in its time, as was the Medical Research Council's Laboratory of Molecular Biology (still a firstrate laboratory) in the 1960s. Now, as then, the research web is constructed on a great diversity of centres - sometimes single people, sometimes an ingenious new instrument, sometimes the lucky coincidence of established senior people's different interests. Britain's trouble, now, is that it has too few centres of acknowledged excellence. Recent attempts to create them out of nothing (by means of the research councils' Interdisciplinary Research Centres, or IRCs) have been undermined by ambivalence about objectives.

The thing that British research most needs is a means of making sure that already outstanding research centres remain excellent. But which are they? The late University Grants Committee, now the Universities (no apostrophe) Funding Council, last year constructed a pecking order of university research departments that would have been even more revealing if overseas researchers had been invigilators. Publicly supported laboratories have not been similarly assessed, but should be. The plan that this information should determine which centres compete in an improving way for the resources available will probably be frustrated by its complexity, and is certainly too slow. But there are other uses to which the data could be put.

The first need is to bless those centres identified as genuinely excellent with the resources that will allow them to remain internationally in the swim - travel money, stipends for visitors and the small change of competitive research of which there has been too little in Britain for too long. The simplest test of a centre's importance should be the number of $\mathrm{PhD}$ graduates from overseas who seek to work there (who should gratefully be helped to do so). Beyond that is the task of finding younger people whose talents promise excellence, and mechanisms by which they can also be supported generously.

But that can be only a means of stopping the rot. For the longer haul, there is a need for action on two different fronts. First, the profession of research must be made attractive again, which means fewer apparently arbitrary policy innovations (and reversals), less pressure to work in fields whose interest is externally defined and, uncomfortably for the John Majors of this world, much better pay. Second, there needs to be an understanding that excellent research is not merely worthwhile in itself, but necessary, in Britain now, if there are to be people skilled enough to prosecute applied research successfully. It is no longer a question of whether there is too much of one and too little of the other, but whether there is enough of either.

\section{Towards what unity?}

German reunification makes necessary a broader integration on a wider front.

EAST Germany, as always, is a special case among members of the Soviet-led equivalent of the European Communities, called Comecon. For several decades, it has been the most productive member of its group. Now, after last Sunday's election, it seems certain to become, in a manner still undefined, one of the least advanced parts 